\title{
Editorial
}

\section{Genome Size}

\author{
Johann Greilhuber, ${ }^{1}$ Jaroslav Doležel, ${ }^{2}$ Ilia J. Leitch, ${ }^{3}$ João Loureiro, ${ }^{4}$ and Jan Suda ${ }^{5,6}$ \\ ${ }^{1}$ Department of Systematic and Evolutionary Botany, Faculty of Life Sciences, University of Vienna, \\ Rennweg 14, 1030 Vienna, Austria \\ ${ }^{2}$ Laboratory of Molecular Cytogenetics and Cytometry, Institute of Experimental Botany, Sokolovská 6, \\ 77200 Olomouc, Czech Republic \\ ${ }^{3}$ Jodrell Laboratory, Royal Botanical Gardens, Kew, Richmond, Surrey TW9 3AD, UK \\ ${ }^{4}$ Centre for Functional Ecology, Department of Life Sciences, University of Coimbra, P.O. Box 3046, 3001-401 Coimbra, Portugal \\ ${ }^{5}$ Department of Botany, Faculty of Science, Charles University in Prague, Benátská 2, 12801 Prague, Czech Republic \\ ${ }^{6}$ Academy of Sciences, Institute of Botany, Prühonice 1, 25243 Prague, Czech Republic
}

Correspondence should be addressed to Johann Greilhuber, johann.greilhuber@univie.ac.at

Received 6 June 2010; Accepted 6 June 2010

Copyright (๑) 2010 Johann Greilhuber et al. This is an open access article distributed under the Creative Commons Attribution License, which permits unrestricted use, distribution, and reproduction in any medium, provided the original work is properly cited.

The beginning of the third millennium has been an exciting time for biologists and geneticists in particular, as it is now possible to read DNA sequences at rates equivalent to a hundred human genomes per week and identify, in a high-throughput manner, differences between genomic loci as small as a single base pair. This rapid progress in genomics has led to the advent of metagenomics, which delivers genomic sequences of organisms occupying certain environments, and population genomics, which focuses on the genomes of many individuals to unravel patterns of neutral and adaptive variation in genomes. Such advances continue to dramatically improve our understanding of the structure of genetic information, its evolution and function, and provide us with the knowledge and tools that have the potential to revolutionize human healthcare, biotechnology, agriculture, and environmental protection.

While we can pinpoint minute changes in DNA sequences, identify chemical modifications of nuclear bases, and link these changes to the phenotype, we continue to be puzzled by the large variation in the size of the genome itself, of which there seems to be no rational explanation. Nevertheless, in seeking to understand the biological basis of this diversity and to understand its adaptive value, researchers have long searched for ecological, evolutionary, and taxonomic interpretations. While early observations that the amount of nuclear DNA did not correlate with organismal complexity were referred to as the "C-value paradox" [1], this was renamed the " $\mathrm{C}$-value enigma" following the realization that much of the variation was due to repetitive DNA [2]. This change in terminology reflected the fact that whilst the basis of the variation in genome size was now understood (i.e., difference in amount of repetitive DNA), there were still many unanswered questions. Indeed, even today, with the mechanisms leading to genome size variation appearing to be well understood, the forces which drive this variation and determine the size of nuclear genome remain puzzling and there is no doubt that the " $\mathrm{C}$-value problem" will stay with us for many years to come.

The observation of the immense variation in genome size raised the quest for biological correlates, stability versus plasticity, function versus effect, and selective significance versus inertness. Various hypotheses were put forward, with the "nucleotype hypothesis" by M. D. Bennett [3] playing a seminal role. He proposed that the DNA of an organism could influence its phenotype in two distinct ways, first through its informational content (genotype), and secondly, through the physical effects of its mass and volume (nucleotype) which could impose absolute limits on the range of phenotypes expressed by genic control. Thus biologists learnt that in addition to the environment and genotype, which influence the phenotype and hence adaptation and niche occupation, the nucleotype could also influence the phenotype largely through effects at the nuclear level such as cell size and cell cycle time [4]. 
An important prerequisite to study the biological role of genome size and its evolutionary changes was the availability of a sufficient amount of data on genome size for representative taxa [5]. The development of a "Plant DNA C-values database" by M. D. Bennett and I. J. Leitch was invaluable in this regard [6] as it provided a lighthouse for those studying genome size variation in plants. Since its launch in 2001, it has been used extensively to search for genome size, to find enough data to describe changes in genome size during evolution and speciation as well as to develop and test hypotheses on the biological significance of genome size variation. Currently the database contains genome size data for 5152 plant species (4429 angiosperms, 207 gymnosperms, 87 pteridophytes, 176 bryophytes, and 253 algae) compiled from over 500 original reference sources with a further update of over 1800 species of angiosperms expected by the end of 2010 . On average the database receives over 2000 hits per month.

The first generation of researchers quantifying DNA amounts struggled with the lack of suitable approaches and instruments and largely used biochemical methods, which produced average values from many cells. Progress was made by the introduction of Feulgen microspectrophotometry, which provided a tool to measure DNA amounts in single cells. This method was widely adopted and led to the generation of genome size data for a vast number of species. The spectrum of methods suitable for plants expanded considerably in 1983, when D. W. Galbraith et al. [7] developed a protocol for measuring DNA content by flow cytometry. The method was shown to be convenient and rapid and has enabled large-scale studies to be undertaken, the scope of which would have been inconceivable using other methods. Flow cytometry is now almost exclusively used in botanical genome size research, not only because of the superiority of the method but also as a result of the increasing availability of affordable instruments. This contrasts with the situation with Feulgen densitometry where the old cytophotometer systems are now technically obsolete. It should be noted that while image cytometry has the potential to replace microdensitometry, to date this method has not been used extensively in plant sciences.

While acknowledging the dominance of flow cytometry, it should be noted that Feulgen densitometry still remains an important tool, for example to solve some methodological problems as described in this issue [8]. While there is still a need to improve DNA flow cytometry methods to enable reliable data on DNA amounts to be generated, current evidence indicates that this technique will continue to be instrumental in expanding research on genome size, making it a prosperous research area. But no matter what methods will be used to estimate the size of nuclear genomes, it seems safe to predict that future studies will increasingly incorporate tools of molecular biology and genomics with the hope of unravelling one of the many secrets of Mother Nature.

As the guest editors of this thematic issue of Journal of Botany, we have great pleasure in introducing sixteen highly valuable and stimulating reviews and original investigations. The topics range from methodological innovations for measuring nuclear DNA amount to investigations on the nucleotype theory and evolutionary phenomena at the quantitative and molecular level. Although the nucleotype theory may answer many questions as to the biological role of genome size, the evolution of genome size still has facets which are poorly understood, and indeed it seems likely that additional factors will be uncovered of which we are currently unaware.

The body of papers that constitute this special issue is led by the focal review of I. J. Leitch et al. (Kew and London, UK; and New Haven, Connecticut, USA) on "Genome size dynamics and evolution in monocots" [9]. This paper provides a detailed analysis of the physical genomic characters and genome size diversification across all monocot orders, conducted within a stringent phylogenetic context. It becomes clear that different monocot orders have followed distinct modes of genome size and chromosome evolution, and that several major increases and decreases have occurred.

J. M. Beaulieu et al. (New Haven, Connecticut; Durham, North Carolina, USA; and Kew, UK) use statistical modelling to analyse the effect of growth form on the tempo of genome size evolution in angiosperms, using the monocots and Fabaceae as target groups [10]. Rates of genome size evolution were found to be dependent on growth form with woody taxa evolving slower than herbaceous ones. This difference likely reflects, in part, the longer generation times in woody angiosperms.

In a timely and in-depth review, C. E. Grover and J. F. Wendel (Ames, Iowa, USA) analyse the various mechanisms of accumulation and removal of transposable DNA elements in the nuclear genome, which lead to the enormous variation observed, including an overview of the epigenetic controls and the population level processes which may operate [11].

T. Eilam et al. (Tel Aviv, Israel; Rehovot, Israel) review the exciting findings of rapid genome downsizing in natural and synthetic allopolyploids and diploidized autopolyploids in the Triticeae, which is in contrast to the additive genome sizes typically found in autopolyploids [12].

Extreme $C$-values are of special interest to flow cytometrists and researchers in genome size. B. J. M. Zonneveld (Leiden, The Netherlands) reports the unexpected discovery of new upper extremes in angiosperm genome size and corrects older values measured using classical Feulgen scanning densitometry [13]. Not unexpectedly, these new extremes are found in the monocot family Melanthiaceae and the eudicot family Viscaceae.

The nucleotype theory and ecological adaptation are the topic or at least an essential focus of four investigations.

M. H. Hoffmann et al. (Gatersleben and HalleWittenberg, Germany) present the results of a comparative study looking at genome size and chromosome number variation, phylogenetic relationships, and differences in developmental rates and reproductive success in Arabidopsis and cooccurring Olimarabidopsis pumila, Arabis montbretiana, and A. auriculata (Brassicaceae) from Uzbekistan [14]. They observed correlations between $1 \mathrm{Cx}$-values and developmental rates and various phenological characters.

C. A. Knight et al. (San Louis Obispo, California, USA; Tartu, Estonia; and New Haven, Connecticut, USA) investigate the relationship between pollen grain size and 
C-value across a phylogenetically broad sample of species and find no significant global correlation (except, a big split between gymnosperms and angiosperms) [15]. Their study highlights the dangers of extrapolating from small-scale analyses, which have suggested that genome size and pollen size were positively correlated, and hence demonstrates that pollen size cannot be used for estimating genome size of ancient taxa.

A. Gruner et al. (San Louis Obispo, California, USA) present the first results from a study aimed at investigating the relationship between genome size and apical root meristem growth rates in eight species of eudicots [16]. Using a novel approach involving time lapse microscopic image analysis they found that root growth was negatively correlated with genome size. This observation has a strong explanatory potential for the prevalence of small genomes in angiosperms.

E. M. Temsch et al. (Vienna, Austria) reappraise a recently published paper on the differential survival of plant species under conditions of heavy metal pollution [17]. The finding that increasing soil pollution with lead along a gradient goes parallel with the loss of species having larger genomes is fully confirmed by this new study, in which flow cytometry was used instead of DNA image densitometry.

Plant biosystematics has enormously profited from the introduction of nuclear DNA content measurement methods and in particular flow cytometry and is a dominating topic within the genome size discipline. Five papers of this special issue of Journal of Botany fall closely within this topic.

O. Hidalgo et al. (Athens, Ohio, USA; Montpellier, France; Barcelona, Spain; Kew, UK; and Barcelona, Spain) present the first large-scale genome size study in 36 species of Valerianaceae, backed by a molecular phylogeny and many chromosome counts [18]. A more than 20-fold variation in C-values, from an extremely low $0.4 \mathrm{pg}$ to $8.32 \mathrm{pg} / 2 \mathrm{C}$, is reported. Changes in the basic chromosome number and genome size characterize major morphological shifts in the evolutionary history of the family.

M. Höfer (Dresden, Germany) and A. Meister (Gatersleben, Germany) provide a nearly complete overview of genome sizes in cultivated and wild apple, 26 primary species and 20 hybrid species, and show correlations of genome size with geographical distribution and taxonomic grouping, as well as genome downsizing in some of the intraspecific polyploids [19].

B. J. M. Zonneveld (Leiden, The Netherlands) presents a complete dataset on Hepatica (Ranunculaceae) and demonstrates that contrary to published C-values, polyploid taxa of this genus have downsized their genomes [20].

K. Anamthawat-Jónsson et al. (Reykjavik, Iceland; Vienna, Austria) report on studies investigating the morphology, ploidy, introgression, and genome size (using both Feulgen densitometry and flow cytometry) in Icelandic birch species Betula nana, B. pubescens, and hybrids [8]. The exceptional constancy of the monoploid genome size at all three levels of ploidy is surprising in view of the different taxonomic position of the parental species and otherwise frequent occurrence of downsized genomes in polyploids and hybrids.
Endopolyploidy is an important phenomenon of tissue differentiation and has been widely investigated in angiosperms, but seldom in the bryophytes.

J. D. Bainard and S. G. Newmaster (Guelph, Ontario, Canada) address this gap by presenting the first study investigating the prevalence of endopolyploidy in bryophytes [21]. Endopolyploidy was observed in all of the moss species studied, with the exception of those belonging to the genus Sphagnum. Endopolyploidy was also noted to be absent in liverworts.

Methodological innovations in flow cytometry of plants are of the upmost importance and are the focus of two papers of the special issue and play a role also in a third one.

I. Jedrzejczyk and E. Sliwinska (Bydgoszcz, Poland) compare the performance of flow cytometry methodologies for the proper isolation of nuclei from leaves and seeds in 11 species of Rosaceae, a family known to be technically difficult because of the prevalence of secondary compounds in almost all tissues [22]. The authors find that seeds are the material of choice for genome size studies rather than leaves because of the absence of DNA staining inhibitors.

T. C. R. Silva et al. (Viçosa, Brazil) tackle a long-standing and hitherto unsolved question, that is, is fixed root tip material suitable for flow cytometry studies. They present a protocol focused on cell cycle studies [23]. Apart from this application, there is much still to be explored in the potential of this method for utilizing fixed and stored plant material collected in the wild.

K. Anamthawat-Jónsson et al. (see above) on Icelandic birch are mentioned once again here as their paper reports that decorticated dormant twigs (harvested in winter) are suitable vegetative material (and probably the only type of material of possible use) for flow cytometric ploidy and genome size determination in Betula, a woody plant genus known to be problematic for genome size studies due to its high phenolic content [8].

It is a pleasant duty to express our deepest thanks to the authors for accepting our invitation, their willingness to share their knowledge and research results, and for timely submission of authoritative reviews and original research articles. We appreciate the time they devoted to this endeavour and we hope that together we have created a useful resource for all interested in plant genome size. We wish you a nice and inspiring reading.

Johann Greilhuber
Jaroslav Doležel
Ilia J. Leitch
João Loureiro
Jan Suda

\section{References}

[1] C. A. Thomas Jr., "The genetic organization of chromosomes," Annual Review of Genetics, vol. 5, pp. 237-256, 1971.

[2] T. R. Gregory, "Coincidence, coevolution, or causation? DNA content, cell size, and the C-value enigma," Biological Reviews, vol. 76, no. 1, pp. 65-101, 2001. 
[3] M. D. Bennett, "The duration of meiosis," Proceedings of the Royal Society of London. Series B, vol. 178, no. 1052, pp. 277299, 1971.

[4] I. J. Leitch and M. D. Bennett, "Genome size and its uses: the impact of flow cytometry," in Flow Cytometry with Plant Cells: Analysis of Genes, Chromosomes and Genomes, J. Doležel, J. Greilhuber, and J. Suda, Eds., pp. 153-176, Wiley-VCH, Weinheim, Germany, 2007.

[5] M. D. Bennett and J. B. Smith, "Nuclear DNA amounts in angiosperms," Philosophical Transactions of the Royal Society of London. Series B, vol. 274, no. 933, pp. 227-274, 1976.

[6] M. D. Bennett and I. J. Leitch, "Plant DNA C-values Database," October 2005, http://data.kew.org/cvalues/.

[7] D. W. Galbraith, K. R. Harkins, J. M. Maddox, N. M. Ayres, D. P. Sharma, and E. Firoozabady, "Rapid flow cytometric analysis of the cell cycle in intact plant tissues," Science, vol. 220, no. 4601, pp. 1049-1051, 1983.

[8] K. Anamthawat-Jónsson, Æ. Th. Thórsson, E. M. Temsch, and J. Greilhuber, "Icelandic birch polyploids - the case of a perfect fit in genome size," Journal of Botany, vol. 2010, Article ID 347254, 9 pages, 2010.

[9] I. J. Leitch, J. M. Beaulieu, M. W. Chase, A. R. Leitch, and M. F. Fay, "Genome size dynamics and evolution in monocots," Journal of Botany, vol. 2010, Article ID 862516, 18 pages, 2010.

[10] J. M. Beaulieu, S. A. Smith, and I. J. Leitch, "On the tempo of genome size evolution in angiosperms," Journal of Botany, vol. 2010, Article ID 989152, 8 pages, 2010.

[11] C. E. Grover and J. F. Wendel, "Recent insights into mechanisms of genome size change in plants," Journal of Botany, vol. 2010, Article ID 382732, 8 pages, 2010.

[12] T. Eilam, Y. Anikster, E. Millet, J. Manisterski, and M. Feldman, "Genome size in diploids, allopolyploids and autopolyploids of Mediterranean Triticeae," Journal of Botany, vol. 2010, Article ID 341380, 12 pages, 2010.

[13] B. J. M. Zonneveld, "New record holders for maximum genome size in eudicots and monocots," Journal of Botany, vol. 2010, Article ID 527357, 4 pages, 2010.

[14] M. H. Hoffmann, H. Schmuths, C. Koch, A. Meister, and R. M. Fritsch, "Comparative analysis of growth, genome size, chromosome numbers and phylogeny of Arabidopsis thaliana and three cooccurring species of the Brassicaceae from Uzbekistan," Journal of Botany, vol. 2010, Article ID 504613, 8 pages, 2010.

[15] C. A. Knight, R. B. Clancy, L. Götzenberger, L. Dann, and J. M. Beaulieu, "On the relationship between pollen size and genome size," Journal of Botany, vol. 2010, Article ID 612017, 7 pages, 2010.

[16] A. Gruner, N. P. Hoverter, T. Smith, and C. A. Knight, "Genome size is a strong predictor of root meristem growth rate," Journal of Botany, vol. 2010, Article ID 390414, 4 pages, 2010.

[17] E. M. Temsch, W. Temsch, L. Ehrendorfer-Schratt, and J. Greilhuber, "Heavy metal pollution, selection, and genome size: the species of the Zerjav study revisited with flow cytometry," Journal of Botany, vol. 2010, Article ID 596542, 11 pages, 2010.

[18] O. Hidalgo, J. Mathez, S. Garcia, T. Garnatje, J. Pellicer, and J. Vallès, "Genome size study in the Valerianaceae: first results and new hypotheses," Journal of Botany, vol. 2010, Article ID 797246, 19 pages, 2010.

[19] M. Höfer and A. Meister, "Genome size variation in Malus species," Journal of Botany, vol. 2010, Article ID 480873, 8 pages, 2010 .
[20] B. J. M. Zonneveld, "Genomes in Hepatica Mill: (Ranunculaceae) show a relative loss of DNA, not a gain, in polyploids," Journal of Botany, vol. 2010, Article ID 758260, 7 pages, 2010.

[21] J. D. Bainard and S. G. Newmaster, "Endopolyploidy in bryophytes: widespread in mosses and absent in liverworts," Journal of Botany, vol. 2010, Article ID 316356, 7 pages, 2010.

[22] I. Jedrzejczyk and E. Sliwinska, "Leaves and seeds as materials for flow cytometric estimation of the genome size of 11 Rosaceae woody species containing DNA-staining inhibitors," Journal of Botany, vol. 2010, Article ID 930895, 9 pages, 2010.

[23] T. C. Ribeiro Silva, I. S. Abreu, and C. R. Carvalho, "Improved and reproducible flow cytometry methodology for nuclei isolation from single root meristem," Journal of Botany, vol. 2010, Article ID 320609, 7 pages, 2010. 

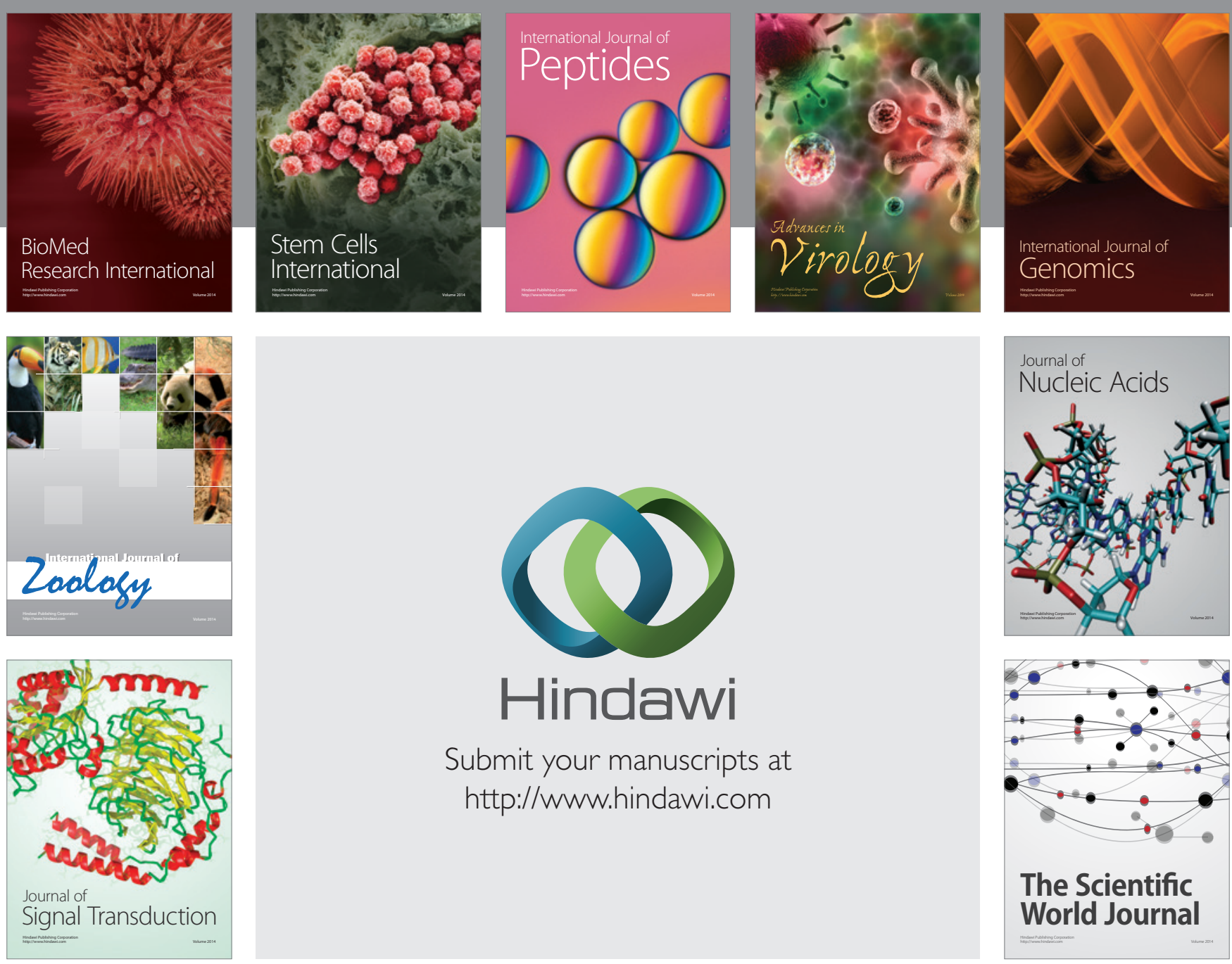

Submit your manuscripts at

http://www.hindawi.com
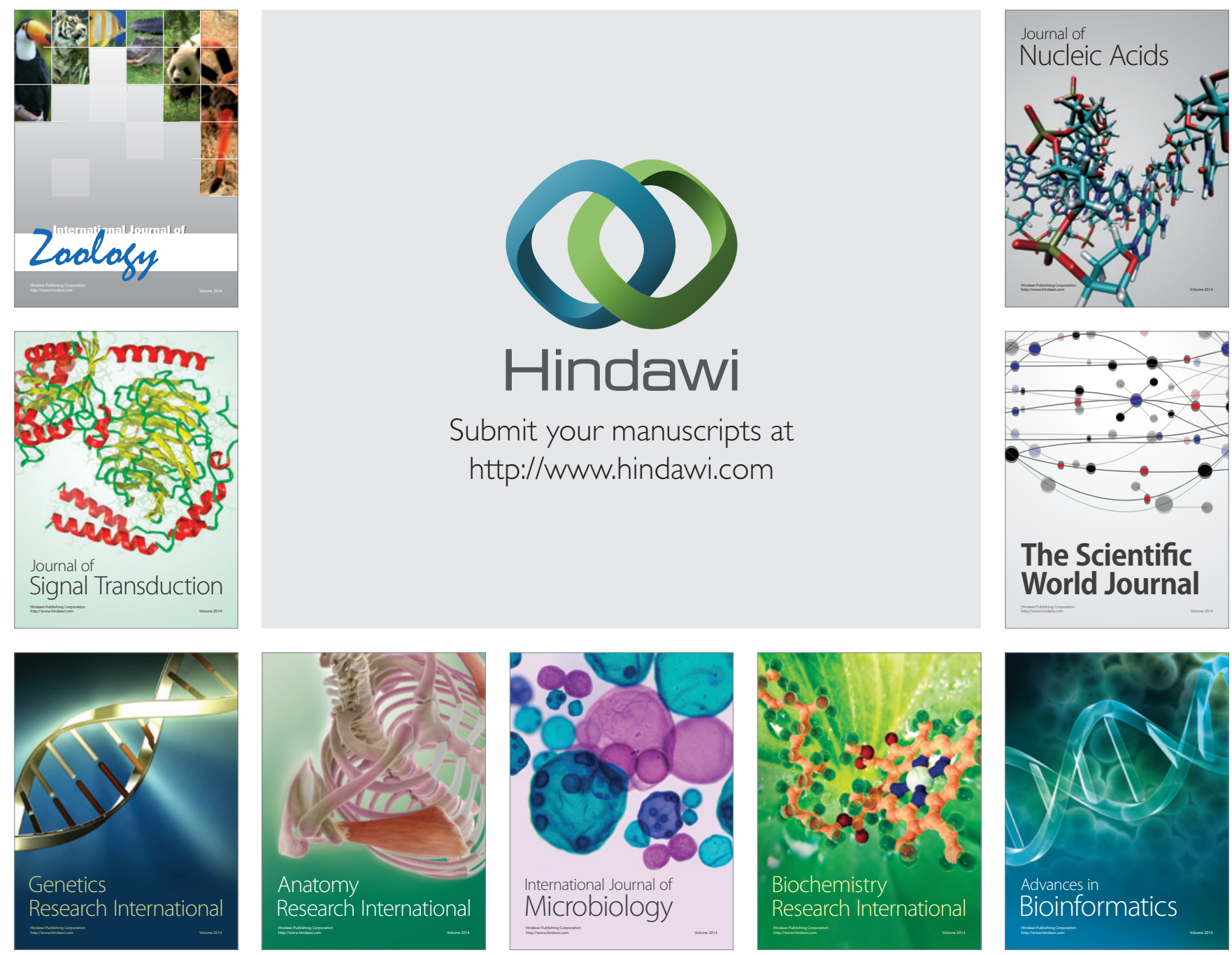

The Scientific World Journal
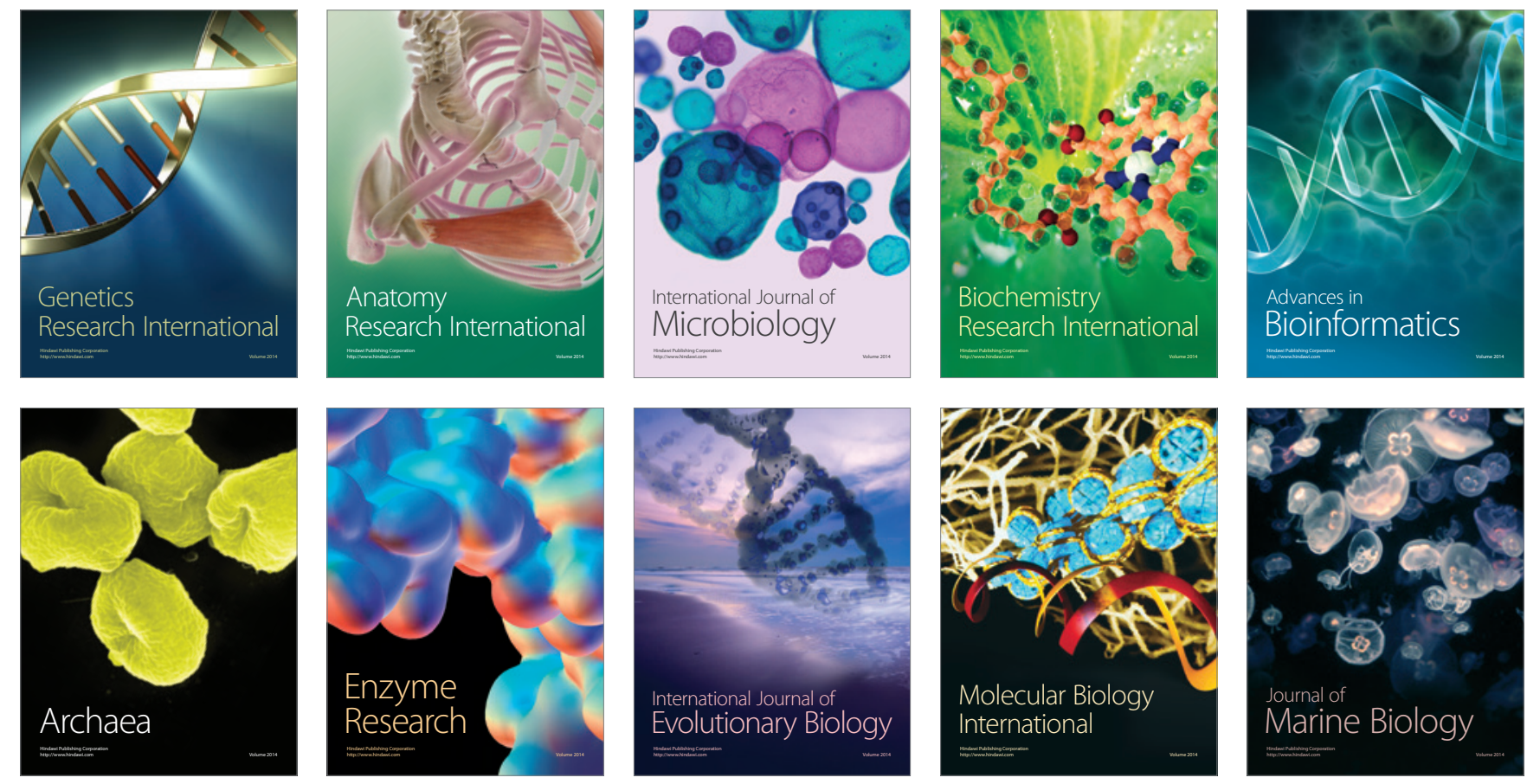